\title{
Patient Dignity at The End-Of-Life: Is it Possible in Critical Care? Jose Granero-Molina
}

Nursing, Physiotherapy and Medicine Department. Almería University, Carretera Sacramento, S/No, La cañada de San Urbano (04120), Almería, Spain

"Corresponding author: Jose Granero-Molina, Nursing, Physiotherapy and Medicine Department. Almería University, Carretera Sacramento, S/N, La cañada de San Urbano (04120), Almería, Spain, E-mail: jgranero@ual.es

Rec date: Oct 19, 2015, Acc date: Oct 21, 2015, Pub date: Oct 29, 2015

Copyright: (C) 2015 Jose Granero-Molina. This is an open-access article distributed under the terms of the Creative Commons Attribution License, which permits unrestricted use, distribution, and reproduction in any medium, provided the original author and source are credited.

\section{Introduction}

Recent scientific-technical advances have allowed human beings to develop and carry out projects of an unimaginable magnitude and complexity. However, facing the technical power potential exhibited in "doing", streams of thinking focused on responsibility, judgment and reflecting on the consequences of our actions have emerged [1]. The mission of an ethical awareness does not aim to achieve precision in praxis, as seen in natural science, but instead to do what each particular situation requires from us. No previous ethics would be able to embrace the objectives and procedures constantly presented in a human being's life, nor the consequences of applying them. "Being ethical", as opposed to "being natural", is not solely a set of skills; hence the application of a moral knowledge in the making of decisions, where the "what should be", values and dignity take precedence.

In this context, human dignity plays an important role in the debate regarding advances in medicine, biology and health sciences and their consequences. Assuming responsibility for the treatment and care of another being obliges us to also safeguard their dignity in life and during the process of death. Issues related to death have been becoming increasingly important since the last century, as although biomedical technology has helped to prolong life, the debate regarding the dignity of a dying person continues [2]. Respecting dignity is having profound effects on the healthcare framework for dying patients [3], especially in the context of a critically ill patient visiting the Emergency Department (ED) or being admitted to the Intensive Care Unit (ICU). These medical services, equipped with the best professionals and means for saving lives, are constantly confronted with the mortal nature of human beings - a dichotomy in which the patient's dignity may be put at risk.

Dignity is a vague and multifaceted concept that is difficult to measure [4]. It is also a key concept in health care; however, its practical meaning in the care of a critically ill patient remains unclear. In general, there is certain skepticism regarding the possibility of defining, characterizing and determining human dignity in the care process of such patients [5]. In this respect, we can refer to Kant's moral philosophy to demonstrate that human dignity has a "nonnormative" aspect, one which forms the base and foundation for human rights and medical and nursing ethics [6].

In Kantian terms, any rational being is subject to law and has a duty to treat themselves and others not as a simple means but always and simultaneously as an end in themselves. The need to conduct oneself according to this principle is a duty which does not lie in feelings and emotions, but in an autonomous will. Dignity obeys a law which man bestows upon himself [7]. For Kant, life in itself does not represent the supreme good which has been entrusted to us, nor is it something which we should be most preoccupied with; there are other duties which he places more importance on. A person who values him/herself does not fear death, and this is what allows them to face it calmly and at peace [8]; it is not a case of ensuring human beings have a long life, but instead that they are capable of living it in a dignified way until the end.

Every human being has the right to be treated with dignity [9] and as such, the preservation of dignity has become one of the fundamental ethical pillars in nursing care [10]. Health professionals, nurses and physicians must not forget to maintain privacy, intimacy and dignity [11]. Dying with dignity is vital for the patients, their families and health-care providers, but it displays special characteristics in the ED or the ICU [12].

In terms of prehospital emergencies, due to the patient's suffering and vulnerability it is essential to preserve their dignity. In critical situations, patients may lose control of their body and see themselves approaching death while surrounded by the faces of people unknown to them. Ambulance nursing staff can help to preserve the patient's dignity through their presence and care, protecting the patient's body from being viewed by other people, facilitating communication and ensuring that the patient and his/her family's wishes are respected [13].

In the Emergency Department, patients, family members and health professionals are faced with the futility and limitations of therapies, donot-resuscitate orders, palliative sedation and advance directives. Focused on attending to acute, life-threatening pathologies, caring for a dying patient in the ED can lead to problems related to stress, communication, fear and loneliness, and carries the risk of losing privacy, confidentiality and dignity [12]. For physicians and nurses, the dignity of a dying person in the ED is a value inherent to the person, as is respecting his/her autonomy, allowing accompaniment and respecting human rights [14]. The loss of this dignity may result from the dying person being exposed to a "cold" world, improvised care, a lack of physical space in which to die, family members' obstinacy and/or a lack of a palliative care culture in the ED [15].

The ICU is a singular environment which poses a specific threat to respect and dignity due to the critical conditions of the patients and the stress and the anxiety of family members, together with the highlytechnical nature of the environment $[16,17]$. End of life care in the ICU implies the absence of pain, the ensuring of comfort, the participation of family members, the existence of a clear prognosis and the preservation of dignity [18]. Dying with dignity in the ICU implies understanding the patient as a unique person in their vulnerability; for this reason, professionals must take care with matters related to diagnosis and treatment, but also those related to prevention and palliative care [19]. Professionals can help patients and family 
Citation: Molina JG (2016) Patient Dignity at The End-Of-Life: Is it Possible in Critical Care? . J Nurs Care 5: e127. doi:

Page 2 of 2

members to accept their situation and facilitate their participation in decisions whilst also ensuring the patient is protected [20]. Nurses must acknowledge the importance of shared humanity in the preservation of dignity, which, together with family support, presents a challenge when attending to a dying person in critical care [21]. Being defenseless, unable to talk and having to be cared for may lead to unpleasant or humiliating situations; as such being seen and heard becomes an absolute necessity.

Awareness, moral integrity and behavior continue to be fundamental factors in the care of a critically ill patient. Preserving dignity throughout the process of death requires the role of all those involved in the treatment, care and making of decisions to be examined. The inclusion of a palliative care culture in the ED or the ICU may mark a significant step forward in the conservation of dignity for dying patients.

\section{References}

1. Jonas H (1995) El principio de la responsabilidad: ensayo de una ética para la civilización tecnológica. (The Imperative of Responsibility: In Search of Ethics for the Technological Age). Barcelona, Editorial Herder.

2. Scanlon A, Murphy M2 (2014) Medical futility in the care of noncompetent terminally ill patient: nursing perspectives and responsibilities. Aust Crit Care 27: 99-102

3. Fernández-Sola C, Granero-Molina J, Aguilera Manrique G, CastroSánchez AM, Hernández-Padilla JM, Márquez-Membrive J (2012) New regulation of the right to a dignified dying in Spain: repercussions for nursing. Nurs Ethics 19:619-628.

4. Griffin-Heslin VL (2005) An analysis of the concept dignity. Accid Emerg Nurs 13: 251-257.

5. Koksvik GH (2015) Dignity in Practice: Day-to-Day Life in Intensive Care Units in Western Europe. Med Anthropol 34: 517-532.

6. Rothhaar M (2010) Human dignity and human rights in bioethics: the Kantian approach. Med Health Care Philos 13: 251-257.
7. Kant I (2002) Groundwork for the metaphysics of morals (trans. Wood AW). New Haven, CT: Yale University Press.

8. Kant I (2001) Lectures on ethics (trans. Heath P). Cambridge: Cambridge University Press.

9. Edlund M, Lindwall L, von Post I, Lindström UÅ (2013) Concept determination of human dignity. Nurs Ethics 20: 851-860.

10. Formosa P (2014) Dignity and respect: how to apply Kant's formula of humanity. Philos Forum 45: 49-68.

11. Latour JM, Albarran JW (2012) Privacy, dignity and confidentiality: a time to reflect on practice. Nurs Crit Care 17: 109-111.

12. Guo Q, Jacelon CS (2014) An integrative review of dignity in end-of-life care. Palliat Med 28: 931-940.

13. Abelsson A, Lindwall L (2015) What is dignity in prehospital emergency care? Nurs Ethics .

14. Fernández-Sola C, Cortés MM, Hernández-Padilla JM, Torres CJ, Terrón JM, Granero-Molina J (2015) Defining dignity in end-of-life care in the emergency department. Nurs Ethics.

15. Beckstrand RL, Rasmussen RJ, Luthy KE, Heaston S (2012) Emergency nurses' perception of department design as an obstacle to providing end-oflife care. J Emerg Nurs 38: e27-32.

16. Nyholm L, Koskinen CA (2015) Understanding and safeguarding patient dignity in intensive care. Nurs Ethics .

17. Aboumatar H, Forbes L, Branyon E, Carrese J, Geller G, et al. (2015) Understanding treatment with respect and dignity in the intensive care unit. Narrat Inq Bioeth 5: 55A-67A.

18. Kirchhoff KT, Spuhler V, Walker L, Hutton A, Cole BV, et al. (2000) Intensive care nurses' experiences with end-of-life care. Am J Crit Care 9: 36-42.

19. Cook D, Rocker G (2014) Dying with dignity in the intensive care unit. N Engl J Med 370: 2506-2514.

20. Pattison N, Carr SM, Turnock C, Dolan S (2013) 'Viewing in slow motion': patients', families', nurses' and doctors' perspectives on end-of-life care in critical care. J Clin Nurs 22: 1442-1454.

21. Heidari MR, Norouzadeh R (2014) Supporting families of dying patients in the intensive care units. Holist Nurs Pract 28: 316-322. 